\title{
Incubação do calcário e as características químicas de solos com texturas diferentes
}

\author{
Lucas MARASCHIN¹, José Fernando SCARAMUZZA1 ${ }^{1}$ Cristiane Ramos VIEIRA2*
}

\author{
${ }^{1}$ Programa de Pós-Graduação em Agricultura Tropical, Universidade Federal de Mato Grosso, Cuiabá, MT, Brasil \\ (ORCID: 0000-0002-0824-5032; 0000-0003-3920-7802) \\ ${ }^{2}$ Faculdade de Agronomia, Universidade de Cuiabá, Cuiabá, MT, Brasil. \\ *E-mail: ramosvieira009@yahoo.com.br (ORCID: 0000-0003-1936-1343)
}

Recebido em: 26/06/2018; Aceito em: 18/10/2019; Publicado em: 04/02/2020.

\begin{abstract}
RESUMO: A calagem interfere na disponibilidade de nutrientes, uma vez que recondiciona o solo. Essa mudança pode ser favorável ou não, dependendo da cultura a ser implantada e do solo a ser corrigido. Diante disso, realizou-se experimento com o objetivo de avaliar os efeitos do calcário, cuja quantidade foi calculada seguindo o método da incubação $\mathrm{com} \mathrm{CaCO}_{3}$, nas características químicas de dois solos, um com textura arenosa e outro com textura argilosa. Primeiramente, foi efetuada a incubação do solo com o calcário, que foi mantido em sacolas plásticas por 40 dias, considerando os tipos de solos estudados. A quantidade de calcário dependeu das doses testadas, que foram distribuídas em delineamento inteiramente casualizado, constituindo 10 tratamentos (doses) e três repetições, sendo: 0,0;0,5;1,0;2,5; 5,0; 7,5; 10,0; 12,5; 15,0 e 20,0 t ha-1 . Após incubação, realizaram-se as análises químicas dos solos. A elevação das doses de calcário, aplicadas ao Latossolo Vermelho distrófico, proporcionou alterações nos teores de $\mathrm{Ca}, \mathrm{Mg}, \mathrm{H}, \mathrm{Al}$ e $\mathrm{Fe}$; que culminaram em alterações em características como $\mathrm{pH}, \mathrm{CTC}, \mathrm{V} \%$ e $\mathrm{m} \%$, tanto quando a textura deste foi argilosa, quanto quando foi média.
\end{abstract}

Palavras-chave: calagem; fração textural; $\mathrm{CaCO}_{3}$; correção do solo.

\section{Method of incubation with limestone in the chemical characteristics of soils with different textures}

\begin{abstract}
Liming interferes on the availability of nutrients, because it reconditions the soil. This change may or may not be favorable, depending on the culture to be implanted and the soil to be corrected. For this, a experiment was realized with the objective of to evaluate the effects of limestone, that the quantity was calculated using the method of incubation with $\mathrm{CaCO}_{3}$, in the chemical characteristics of two soils, one with medium texture and the other with a clayey texture. First, the soil was incubated with the limestone and the material was kept in plastic bags for 40 days, considering the types of soils studied. The amount of limestone depended on the doses tested, which were distributed in a completely randomized design, constituting 10 treatments (doses) and three replications, that were: $0.0 ; 0.5 ; 1.0 ; 2.5 ; 5.0 ; 7.5 ; 10.0 ; 12.5 ; 15.0$ and $20.0 \mathrm{t} \mathrm{ha}^{-1}$. After incubation, analyzes of the chemical characteristics of the soils, were carried out. The increase of limestone doses, applied to the dystrophic Red Latosol, caused alterations in $\mathrm{Ca}, \mathrm{Mg}, \mathrm{H}, \mathrm{Al}$ and $\mathrm{Fe}$ contents; culminating in changes in characteristics as $\mathrm{pH}, \mathrm{CTC}, \mathrm{V} \%$ and $\mathrm{m} \%$, when the texture was clayey and medium. Keywords: liming; fraction textural; $\mathrm{CaCO}_{3}$; soil correction.
\end{abstract}

\section{INTRODUÇÃO}

Os solos sob Cerrado ocupam a maior parte do território brasileiro, e normalmente, são ácidos e de baixa fertilidade. Dentre os tipos de solos encontrados, estão os Latossolos, que são caracterizados pela baixa fertilidade natural. Para plantios realizados nessas condições, a prática da calagem é fundamental. De acordo com Oliveira et al. (2010) a calagem tem se destacado como a prática mais utilizada na agricultura para adequar as propriedades químicas do solo às necessidades das culturas.

Com a calagem, eleva-se o $\mathrm{pH}$ do solo, neutraliza-se o $\mathrm{Al}^{3+}$ tóxico e adiciona-se $\mathrm{Ca}^{2+}$ e $\mathrm{Mg}^{2+}$ ao solo, proporcionando condições favoráveis ao crescimento do sistema radicular e absorção de água e nutrientes pelas plantas (ZANDONÁ et al., 2015). Essa adequação do pH e o equilíbrio entre os teores de bases no solo, proporciona uma adequada disponibilidade da maioria dos nutrientes para as plantas (OLIVEIRA et al., 2015). De acordo com Carmo; Silva (2016), com a prática da calagem, há aumento da concentração de íons e sais (Ca, Mg e K), como consequência da dose de corretivo aplicada, e da magnitude dos efeitos da calagem sobre os processos que regulam a disponibilidade de nutrientes no solo. Além disso, a calagem também diminui a precipitação do $\mathrm{P}$ com o $\mathrm{Al}$ trocável, em função da complexação do $\mathrm{Al}^{3+}$, promovida pelos grupos hidroxila $\left(\mathrm{OH}^{-}\right)$liberados durante a calagem (CARDOSO et al., 2015).

Bambolim et al. (2015) também corroboraram, com sua pesquisa, que o calcário convencional corrige a acidez e eleva a saturação por bases do solo, confirmando seus efeitos de correção da acidez do solo e de suprimento de Ca e $\mathrm{Mg}$. Porém, o calcário tem ação limitada ao local de aplicação, não tendo efeito rápido na redução da acidez de camadas mais 
profundas. Essa redução da acidez ocorre em camadas mais profundas quando o material é incorporado ao solo ou com a lixiviação de carbonatos através do perfil do solo. O que proporciona as melhores condições dos atributos físicos e químicos, resultando em maiores produtividades (BLUM et al., 2013).

Portanto, a dose correta de calcário no solo, considerando a cultura a ser implantada, contribui para que ela atinja o seu maior potencial produtivo, pois, a disponibilidade de nutrientes está intimamente relacionada com a dose de calcário recomendada. Ao passo que, doses inadequadas podem reduzir a disponibilidade dos nutrientes, ou ainda, causar toxidez para as plantas. Para isso, há que se atentar para a forma de calcular a quantidade de calcário necessária. Em estudo com doses crescentes de $\mathrm{CaCO}_{3}$, Sousa et al. (2014) verificaram que o Argissolo Vermelho Amarelo distrófico apresentou características satisfatórias de acidez do solo, com a adição de $8,0 \mathrm{t} \mathrm{ha}^{-1}$ de $\mathrm{CaCO}_{3}$. Enquanto que, a quantidade necessária para neutralização da acidez trocável desse solo foi de $8,8 \mathrm{t} \mathrm{ha}^{-1}$ de $\mathrm{CaCO}_{3}$.

Dessa forma, verifica-se que, as doses recomendadas podem ser estimadas por diferentes métodos, sem que estes estejam relacionados entre si e a maioria deles não se adequam a todos os tipos de solos. Sendo assim, este trabalho teve como objetivo analisar os efeitos da calagem, utilizando o método padrão de incubação com $\mathrm{CaCO}_{3}$, com base nas características químicas de dois solos com texturas diferentes.

\section{MATERIAL E MÉTODOS}

O experimento foi realizado em casa de vegetação, localizadas nas coordenadas $15^{\circ} 36^{\prime} 39,46^{\prime \prime}$ S e $56^{\circ} 3^{\prime} 53,96^{\prime \prime}$ O. Essa casa de vegetação pertencente à Faculdade de Agronomia e Zootecnia (FAAZ), da Universidade Federal de Mato Grosso (UFMT), e se trata de um ambiente sem controle de temperatura e umidade, que possui sombrite nas laterais e é coberto com telha de amianto.

Um dos solos utilizados para o experimento foi coletado em região de Cerrado nativo, em área pertencente ao Instituto Federal de Mato Grosso (IFMT), no campus de Campo Verde - MT. Este solo foi classificado como Latossolo Vermelho distrófico, com textura média (TM). O outro solo foi classificado como Latossolo Vermelho distrófico típico e foi coletado na Fazenda Pejuçara, localizada no município de Sorriso - MT e se caracterizou por uma textura argilosa (TA). Os dois tipos de solos foram coletados considerando a camada de até $20 \mathrm{~cm}$ de profundidade. Amostras de ambos foram retiradas, para a caracterização química e física, anteriormente à incubação com o calcário. Os resultados estão apresentados na Tabela 1.

O calcário utilizado no experimento foi caracterizado como dolomítico, com PRNT igual a 100\%, contendo 24,5\% $\mathrm{CaO}$ e $17,5 \% \mathrm{MgO}$. Esse material foi utilizado para compor as doses testadas, para cada um dos solos analisados.

A partir dos resultados das análises dos solos, foram realizados os cálculos para recomendação de calagem utilizando o método da incubação com $\mathrm{CaCO}_{3}$, nas seguintes doses: 0,$0 ; 0,5 ; 1,0 ; 2,5 ; 5,0 ; 7,5 ; 10,0 ; 12,5 ; 15,0$ e 20,0 t ha-1. Essas doses constituíram os 10 tratamentos testados, que foram distribuídos em delineamento inteiramente casualizado, com três repetições, resultando em 30 unidades experimentais para cada tipo de solo.
O solo foi incubado juntamente com o calcário, nas doses referentes a cada tratamento, por 40 dias, em sacolas plásticas com capacidade para dois quilos, mantendo, diariamente, a umidade na capacidade de campo de $80 \%$. Após esse período, os solos foram secos em estufa de circulação forçada de ar a $60^{\circ} \mathrm{C}$ até massa constante e, em seguida, foram retiradas amostras para as realizações das análises químicas seguindo metodologia da Embrapa (2011).

Tabela 1. Características químicas e físicas dos solos utilizados no experimento.

Table 1. Chemical and physical characteristics of the soils used in the experiment.

\begin{tabular}{|c|c|c|}
\hline \multirow{2}{*}{ Características } & \multicolumn{2}{|c|}{ Texturas } \\
\hline & Média & Argilosa \\
\hline pH em água & 4,6 & 4,5 \\
\hline $\mathrm{pH} \mathrm{em} \mathrm{CaCl}_{2}$ & 4,0 & 3,9 \\
\hline $\mathrm{P}\left(\mathrm{mg} \mathrm{dm}^{-3}\right)$ & 1,4 & 1,1 \\
\hline $\mathrm{K}\left(\mathrm{mg} \mathrm{dm}^{-3}\right)$ & 64 & 32 \\
\hline $\mathrm{Zn}\left(\mathrm{mg} \mathrm{dm}^{-3}\right)$ & 0,9 & 0,7 \\
\hline $\mathrm{Cu}\left(\mathrm{mg} \mathrm{dm}^{-3}\right)$ & 0,5 & 0,4 \\
\hline $\mathrm{Fe}\left(\mathrm{mg} \mathrm{dm}^{-3}\right)$ & 207 & 264 \\
\hline $\operatorname{Mn}\left(\mathrm{mg} \mathrm{dm}^{-3}\right)$ & 8,6 & 5,0 \\
\hline $\mathrm{S}\left(\mathrm{mg} \mathrm{dm}^{-3}\right)$ & 0,71 & 0,74 \\
\hline $\mathrm{B}\left(\mathrm{mg} \mathrm{dm}^{-3}\right)$ & 8,3 & 9,2 \\
\hline $\mathrm{Ca}\left(\mathrm{cmol}_{\mathrm{c}} \mathrm{dm}^{-3}\right)$ & 0,1 & 0,1 \\
\hline $\mathrm{Mg}\left(\mathrm{cmol}_{\mathrm{c}} \mathrm{dm}^{-3}\right)$ & 0,1 & 0,1 \\
\hline $\mathrm{Al}\left(\mathrm{cmol}_{\mathrm{c}} \mathrm{dm}^{-3}\right)$ & 1,2 & 1,4 \\
\hline $\mathrm{H}\left(\mathrm{cmol}_{\mathrm{c}} \mathrm{dm}^{-3}\right)$ & 3,8 & 6,5 \\
\hline Mat.Org.(g kg-1) & 20,6 & 33,9 \\
\hline Areia $\left(\mathrm{g} \mathrm{kg}^{-1}\right)$ & 643 & 243 \\
\hline Silte $\left(\mathrm{g} \mathrm{kg}^{-1}\right)$ & 84 & 117 \\
\hline $\operatorname{Argila~}\left(\mathrm{g} \mathrm{kg}^{-1}\right)$ & 273 & 640 \\
\hline Densidade do solo $\left(\mathrm{g} \mathrm{cm}^{-3}\right)$ & 1,04 & 1,05 \\
\hline Densidade de partículas $\left(\mathrm{g} \mathrm{cm}^{-3}\right)$ & 2,45 & 2,49 \\
\hline Soma de bases (SB) $\left(\mathrm{cmol}_{\mathrm{c}} \mathrm{dm}^{-3}\right)$ & 0,4 & 0,3 \\
\hline CTC a pH 7,0 $\left(\mathrm{cmol}_{\mathrm{c}} \mathrm{dm}^{-3}\right)$ & 5,3 & 8,1 \\
\hline Saturação por Bases (V) \% & 6,9 & 3,5 \\
\hline Relação Ca/Mg & 1,2 & 1,3 \\
\hline Relação Ca/K & 0,6 & 1,5 \\
\hline Relação Mg/K & 0,5 & 1,2 \\
\hline Saturação por $\mathrm{Ca}(\%)$ & 1,9 & 1,5 \\
\hline Saturação por Mg (\%) & 1,6 & 1,2 \\
\hline Saturação por K (\%) & 3,1 & 1,0 \\
\hline Saturação por H (\%) & 71,5 & 79,9 \\
\hline Saturação por Al (m) (\%) & 75,8 & 82,7 \\
\hline
\end{tabular}

Em cada amostra foram determinados: $\mathrm{pH}$ em $\mathrm{H}_{2} \mathrm{O}$ e em $\mathrm{CaCl}_{2}$ (na proporção 1:2,5). Teores de $\mathrm{Ca}, \mathrm{Mg}$ e de $\mathrm{Al}$, obtidos por meio da extração com $\mathrm{KCl} 1 \mathrm{~N}$ e quantificados por titulometria. Teores de $\mathrm{P}$, de $\mathrm{K}$ e de micronutrientes $(\mathrm{Cu}, \mathrm{Fe}$, Mn e Zn), por extração com Mehlich-1 e quantificados utilizando-se: o método do subcarbonato de bismuto em vitamina $\mathrm{C}$ para determinação do teor de $\mathrm{P}$; o método da fotometria de chama para $\mathrm{K}$, e; a espectrofotometria de absorção atômica para os micronutrientes. A acidez total $(\mathrm{H}$ $+\mathrm{Al}$ ) foi obtida por extração com acetato de cálcio $1 \mathrm{~mol} / \mathrm{L}$ em $\mathrm{pH}$ 7,0 e determinada por titulometria. Enquanto o teor de matéria orgânica foi estimado utilizando-se a queima em mufla. Os resultados das variáveis analisadas $\mathrm{pH} \mathrm{H}_{2} \mathrm{O}, \mathrm{pH}$ $\mathrm{CaCl}_{2}, \mathrm{P}, \mathrm{K}, \mathrm{H}+\mathrm{Al}, \mathrm{Ca}, \mathrm{Mg}, \mathrm{Fe}, \mathrm{m}, \mathrm{SB}$ e $\mathrm{V} \%$ foram submetidos à análise de variância pelo Teste $\mathrm{F}$ (a $1 \%$ e $5 \%$ de significância). Enquanto que, as correlações foram obtidas a 
partir do Teste de Tukey. Posteriormente, foram ajustadas equações de regressão para cada característica e, com base nessas equações, foi possível estimar a disponibilidade de $\mathrm{P}$, $\mathrm{K}, \mathrm{Ca}, \mathrm{Mg}, \mathrm{Fe}, \mathrm{H}, \mathrm{Al}$ e os valores para SB, T, V (\%) e m (\%) nas diferentes doses de calcário e solos estudados.

\section{RESULTADOS}

\subsection{Correlação entre as características químicas}

As variáveis químicas, em estudo, apresentaram correlação com a textura do solo, assim como, com a dose de calcário que foi aplicada em função da quantidade de $\mathrm{CaCO}_{3}$. Essas correlações entre as características químicas estão apresentadas na Tabela 2.

Na Tabela 3 estão apresentadas as equações de regressão que foram obtidas para os atributos químicos analisados, de acordo com a textura do solo e a dose de calcário, aplicada em função da quantidade de $\mathrm{CaCO}_{3}$. Observa-se que, as equações de regressão que melhor se ajustaram aos diferentes atributos avaliados foram as de ordem exponencial, pois esse modelo foi o que melhor explicou a variação dos atributos com o aumento das doses de calcário.

\subsection{Acidez ativa ou $\mathrm{pH}$}

Os valores do $\mathrm{pH}$ em $\mathrm{CaCl}_{2}$ (Figura 1) variaram entre 3,7 e 6,9 no solo TM, nas doses 0,0 e 20,0 t ha ${ }^{-1}$, respectivamente. No solo TA, a variação foi de 4,10 e 6,81, para as mesmas doses. Obtendo-se, assim, valores médios de 5,81 no solo

TM e de 5,39 no solo TA. Quanto aos valores do $\mathrm{pH}$ em $\mathrm{H}_{2} \mathrm{O}$, as tendências observadas foram as mesmas.

Tabela 2. Correlação entre as características químicas, em solo com textura média e com textura argilosa em função das doses de calcário.

Table 2. Correlation between chemical characteristics in soil with medium texture and clayey texture as a function of limestone.

\begin{tabular}{ccc}
\hline Característica & Textura média & Textura argilosa \\
\hline $\mathrm{pH} \mathrm{H} \mathrm{H}_{2} \mathrm{O}$ & $0,89^{* *}$ & $0,98^{* *}$ \\
$\mathrm{pH} \mathrm{CaCl} \mathrm{C}_{2}$ & $0,86^{* *}$ & $0,97^{* *}$ \\
$\mathrm{P}$ & $0,67^{*}$ & 0,26 \\
$\mathrm{~K}$ & 0,13 & $0,77^{* *}$ \\
$\mathrm{H}$ & $-0,90^{* *}$ & $-0,97^{* *}$ \\
$\mathrm{Al}$ & $-0,68^{*}$ & $-0,74^{*}$ \\
$\mathrm{Ca}$ & $0,88^{* *}$ & $0,94^{* *}$ \\
$\mathrm{Mg}$ & $0,80^{* *}$ & $0,92^{* *}$ \\
$\mathrm{Fe}$ & $-0,90^{* *}$ & $-0,86^{* *}$ \\
$\mathrm{Zn}$ & 0,31 & 0,54 \\
$\mathrm{Mn}$ & $-0,25$ & $0,80^{* *}$ \\
$\mathrm{Cu}$ & $-0,09$ & $0,72^{*}$ \\
$\mathrm{SB}$ & $0,85^{* *}$ & $0,93^{* *}$ \\
$\mathrm{M}$ & $-0,65^{*}$ & $-0,71^{*}$ \\
$\mathrm{~V}$ & $0,83^{* *}$ & $0,95^{* *}$ \\
$\mathrm{CTC}$ & $0,84^{* *}$ & 0,50 \\
$\mathrm{MO}$ & 0,33 & $0,81^{* *}$ \\
\hline ** $\mathrm{e}^{*}$ significativo pelo teste $\mathrm{F}(\mathrm{p}<0,01)$. &
\end{tabular}

Tabela 3. Regressão para os atributos químicos estudados, em solos com diferentes texturas, em função das doses de calcário. Table 3. Regression equations for the chemical attributes studied in soils with different textures, as a function of limestone rates.

\begin{tabular}{|c|c|}
\hline Equações de regressão & $\mathrm{R}^{2}$ \\
\hline$\overline{\mathrm{pH} \mathrm{H}} \mathrm{O}_{2} \mathrm{O}_{(\mathrm{TM})}=7,324 \cdot \exp (0,001062 \cdot \mathrm{X})-2,79 \cdot \exp (-0,2609 \cdot \mathrm{X})$ & $0,996^{* *}$ \\
\hline $\mathrm{pH} \mathrm{H}_{2} \mathrm{O}_{(\mathrm{TA})}=1,207 \cdot 10^{4} \cdot \exp (-0,02025 \cdot \mathrm{X})-1,206 \times 10^{4} \cdot \exp (-0,02027 \cdot \mathrm{X})$ & $0,989 * *$ \\
\hline $\mathrm{pH} \mathrm{CaCl}_{2(\mathrm{TM})}=6,925 \cdot \exp \left(-1,379 \cdot 10^{-7} \cdot \mathrm{X}\right)-3,144 \cdot \exp (-0.2869 \cdot \mathrm{X})$ & $0,990^{* *}$ \\
\hline $\mathrm{pH} \mathrm{CaCl} 2(\mathrm{TA})=11,72 \cdot \exp (-0,01062 \cdot \mathrm{X})-7,613 \cdot \exp (-0,05182 \cdot \mathrm{X})$ & $0,995^{* *}$ \\
\hline $\mathrm{Ca}{ }_{(\mathrm{TM})}=3,391 \cdot \exp (-0,006079 \cdot \mathrm{X})-3,203 \cdot \exp (-0,2061 \cdot \mathrm{X})$ & $0,992^{* *}$ \\
\hline $\mathrm{Ca}_{(\mathrm{TA})}=11,99 \cdot \exp (-0,03139 \cdot \mathrm{X})-12,05 \cdot \exp (-0,08053 \cdot \mathrm{X})$ & $0,989 * *$ \\
\hline $\mathrm{Mg}_{(\mathrm{TM})}=2,364 \exp \left(3,27 * 10^{-5} \cdot \mathrm{X}\right)-2,387 \exp (-0,3943 \cdot \mathrm{X})$ & $0,9695^{* *}$ \\
\hline$M g_{(\mathrm{TA})}=2,989 \cdot \exp (0,002456 \cdot \mathrm{X})-2,626 \cdot \exp (-0,1976 \cdot \mathrm{X})$ & $0,9787 * *$ \\
\hline $\mathrm{H}_{(\mathrm{TM})}=2,394 \cdot \exp (-0,2106 \cdot \mathrm{X})$ & $0,951 * *$ \\
\hline $\mathrm{H}_{(\mathrm{TA})}=2962 \cdot \exp (-0,0388 \cdot \mathrm{X})-2956 \cdot \exp (-0,03872 \cdot \mathrm{X})$ & $0,983^{* *}$ \\
\hline $\mathrm{Al}_{(\mathrm{TM})}=1,308 \cdot \exp (-0,8967 \cdot \mathrm{X})+0,08851 \cdot \exp (0,01003 \cdot \mathrm{X})$ & $0,996^{* *}$ \\
\hline $\mathrm{Al}_{(\mathrm{TA})}=1,099 \cdot \exp (-0,5407 \cdot \mathrm{X})+0,0587 \cdot \exp (0,03822 \cdot \mathrm{X})$ & $0,998^{* *}$ \\
\hline $\mathrm{Fe}_{(\mathrm{TM})}=45,71 \cdot \exp (-0,3155 \cdot \mathrm{X})+67,58 \cdot \exp (-0,01154 \cdot \mathrm{X})$ & $0,941 * *$ \\
\hline $\mathrm{Fe}_{(\mathrm{TA})}=44,67 \cdot \exp (-0,7936 \cdot \mathrm{X})+91,49 \cdot \exp (-0,01423 \cdot \mathrm{X})$ & $0,959 * *$ \\
\hline $\mathrm{m}_{(\mathrm{TM})}=71,28 \cdot \exp (-0,9227 \cdot \mathrm{X})+1,041 \cdot \exp (0,03844 \cdot \mathrm{X})$ & $0,996^{* *}$ \\
\hline $\mathrm{m}_{(\mathrm{TA})}=67,52 \cdot \exp (-0,6946 \cdot \mathrm{X})+0,7623 \cdot \exp (0,06844 \cdot \mathrm{X})$ & $0,998^{* *}$ \\
\hline $\mathrm{SB}_{(\mathrm{TM})}=5,469 \cdot \exp (0,0006601 \cdot \mathrm{X})-5,101 \cdot \exp (-0,3089 \cdot \mathrm{X})$ & $0,978^{* *}$ \\
\hline $\mathrm{SB}_{(\mathrm{TA})}=8,287 \cdot \exp (-0,01272 \cdot \mathrm{X})-7,93 \cdot \exp (-0,1705 \cdot \mathrm{X})$ & $0,995^{* *}$ \\
\hline $\mathrm{CTC}_{(\mathrm{TM})}=5,63 \cdot \exp (-((\mathrm{X}-9,704) / 20,83) 2)+-0,4513 \exp (-((\mathrm{X}-0,8331) / 2,026)+1,458 \exp (-((\mathrm{X}-22,49) / 6,593) 2)$ & $0,999 * *$ \\
\hline $\mathrm{CTC}_{(\mathrm{TA})}=14,28 \cdot \exp (-0,03423 \cdot \mathrm{X})-7,043 \cdot \exp (-0,1312 \cdot \mathrm{X})$ & $0,9794 * *$ \\
\hline $\mathrm{V}_{(\mathrm{TM})}=100,4 \cdot \exp (-0,002541 \cdot \mathrm{X})-88,29 \cdot \exp (-0,3457 \cdot \mathrm{X})$ & $0,990 * *$ \\
\hline $\mathrm{V}_{(\mathrm{TA})}=59,59 \cdot \exp (0,01922 \cdot \mathrm{X})-54,4 \cdot \exp (-0,2848 \cdot \mathrm{X})$ & $0,998^{* *}$ \\
\hline
\end{tabular}

\subsection{Acidez não trocável ou $\mathbf{H}^{+}$}

$\mathrm{O}$ teor de $\mathrm{H}^{+}$diminuiu com o aumento das doses de calcário (Figura 2). No solo TM, os teores de $\mathrm{H}^{+}$variaram de 2,41 a $0,00 \mathrm{cmol}_{\mathrm{c}} \mathrm{dm}^{-3}$ e no solo TA variaram entre $5,83 \mathrm{e}$ $0,38 \mathrm{cmol}_{\mathrm{c}} \mathrm{dm}^{-3}$, para as doses de 0 e de 20,0 $\mathrm{t} \mathrm{ha}^{-1}$, respectivamente. Nesse caso, os valores médios totais observados para $\mathrm{H}^{+}$foram de $0,98 \mathrm{cmol}_{\mathrm{c}} \mathrm{dm}^{-3}$ no TM e de $3,38 \mathrm{cmol}_{\mathrm{c}} \mathrm{dm}^{-3}$ no TA.

\subsection{Acidez trocável ou Al trocável}

Os teores de $\mathrm{Al}^{3+}$ (Figura 3) no solo TM diminuíram com o aumento das doses de calcário, apresentando valores de 1,43 (na dose de $0,0 \mathrm{t} \mathrm{ha}^{-1}$ ) a $0,09 \mathrm{cmol}_{\mathrm{c}} \mathrm{dm}^{-3}$ (na dose de 20,0 t ha' ${ }^{-1}$ ) e; de 1,18 a $0,09 \mathrm{cmol}_{\mathrm{c}} \mathrm{dm}^{-3}$, nas doses de 0,0 e 20,0 t $\mathrm{ha}^{-1}$, respectivamente, no solo TA. 


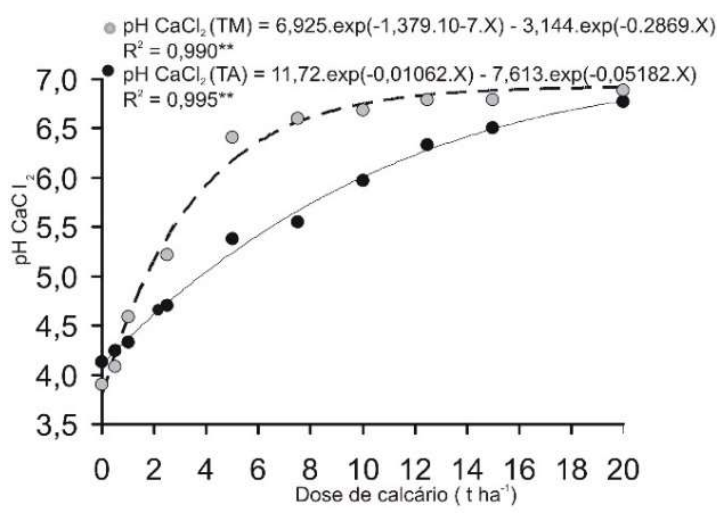

Figura 1. $\mathrm{pH}$ em $\mathrm{CaCl}_{2}$ nos solos com textura média (TM) e com textura argilosa (TA) em função das doses de calcário obtidas pelo método da incubação com $\mathrm{CaCO}_{3}$.

Figure 1. $\mathrm{pH}$ in $\mathrm{CaCl}_{2}$ in soils with medium texture (TM) and clayey texture (TA) as a function of the limestone doses obtained by the $\mathrm{CaCO}_{3}$ incubation method.

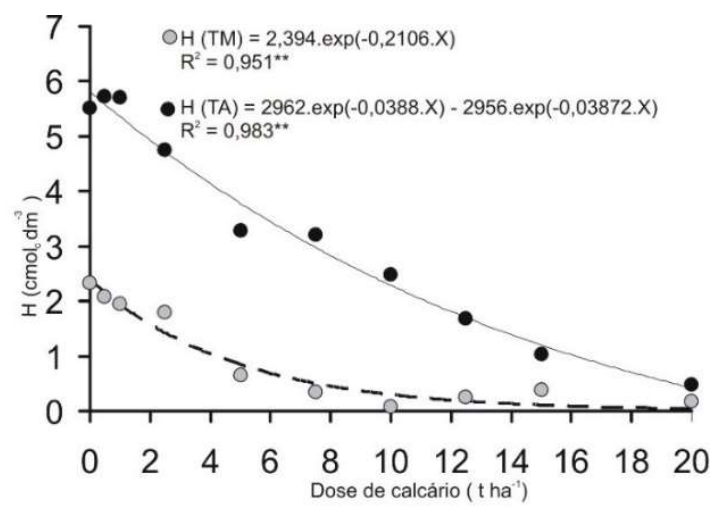

Figura 2. Teores de $\mathrm{H}$ nos solos com textura média (TM) e com textura argilosa (TA) em função das doses de calcário obtidas pelo método da incubação com $\mathrm{CaCO}_{3}$.

Figure 2. $\mathrm{H}$ content in soils with medium texture (TM) and clayey texture (TA) as a function of the limestone doses obtained by the $\mathrm{CaCO}_{3}$ incubation method.

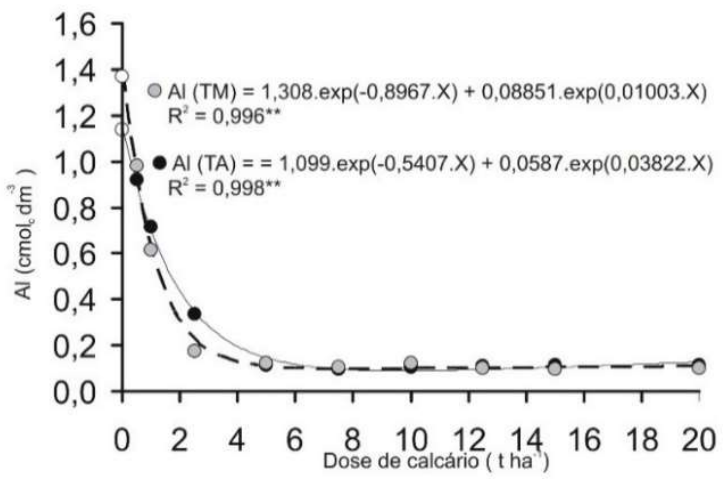

Figura 3. Teores de $\mathrm{Al}$ nos solos com textura média (TM) e com textura argilosa (TA) em função das doses de calcário obtidas pelo método da incubação com $\mathrm{CaCO}_{3}$.

Figure 3. Al content in soils with medium texture (TM) and clayey texture (TA) as a function of the limestone doses obtained by the $\mathrm{CaCO}_{3}$ incubation method.

\subsection{Cálcio}

Os teores de Ca (Figura 4) aumentaram com as doses de calcário, variando de 0,18 a 3,05 $\mathrm{cmol}_{\mathrm{c}} \mathrm{dm}^{-3}$, no solo TM, e de 0,00 a $4,15 \mathrm{cmol}_{\mathrm{c}} \mathrm{dm}^{-3}$, no solo TA (entre as doses de 0,0 e de 20,0 $\mathrm{t} \mathrm{ha}^{-1}$ ). Os teores médios de $\mathrm{Ca}$ na testemunha foram, respectivamente, $0,19 \mathrm{cmol}_{\mathrm{c}} \mathrm{dm}^{-3}$ e $0,06 \mathrm{cmol}_{\mathrm{c}} \mathrm{dm}^{-3}$ para os solos TM e TA.

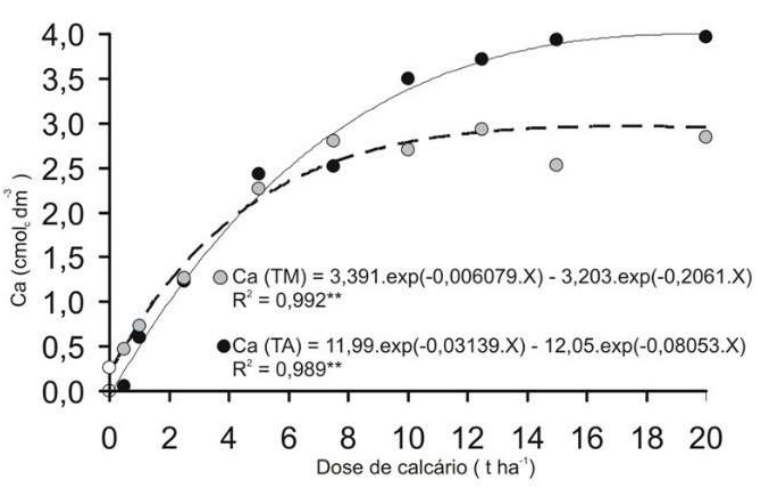

Figura 4. Teores de Ca nos solos com textura média (TM) e com textura argilosa (TA) em função das doses de calcário obtidas pelo método da incubação com $\mathrm{CaCO}_{3}$.

Figure 4. Ca contents in soils with medium texture (TM) and clayey texture (TA) as a function of limestone rates obtained by the $\mathrm{CaCO}_{3}$ incubation method.

\subsection{Magnésio}

Os teores de $\mathrm{Mg}$ (Figura 5) aumentaram com as doses de calcário, observando-se variação entre 0,00 e $2,25 \mathrm{cmol}_{\mathrm{c}}$ $\mathrm{dm}^{-3}$, para as dose de $0,0 \mathrm{t} \mathrm{ha}^{-1}$ e de $20,0 \mathrm{t} \mathrm{ha}^{-1}$, respectivamente, no solo TM; e entre 0,00 e 3,10 $\mathrm{cmol}_{\mathrm{c}} \mathrm{dm}^{-3}$, no solo TA, nas mesmas doses.

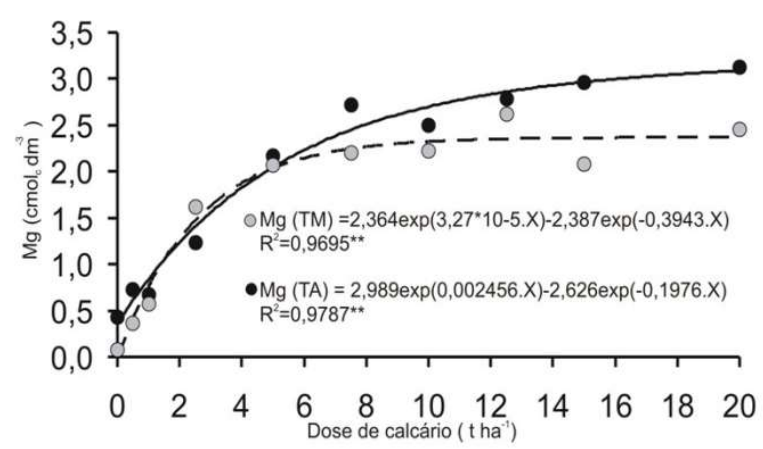

Figura 5. Teores de Mg nos solos com textura média (TM) e com textura argilosa (TA) em função das doses de calcário obtidas pelo método da incubação com $\mathrm{CaCO}_{3}$.

Figure $5 . \mathrm{Mg}$ contents in soils with medium texture (TM) and clayey texture (TA) as a function of the limestone doses obtained by the $\mathrm{CaCO}_{3}$ incubation method.

\subsection{Ferro}

Os teores de Fe (Figura 6) diminuíram com o aumento da dose de $\mathrm{CaCO}_{3}$, independentemente da textura do solo. Com teores que variaram de 122,8 a 47,6 $\mathrm{mg} \mathrm{dm}^{-3}$ no TM; e de 145,4 a 63,9 $\mathrm{mg} \mathrm{dm}^{-3}$ no TA; entre as doses de 0,0 e de 20,0 $\mathrm{tha}^{-1}$.

\subsection{Soma de bases (SB)}

A SB (Figura 7) variou de 0,35 a 5,87 $\mathrm{cmol}_{\mathrm{c}} \mathrm{dm}^{-3}$ no solo TM e de 0,53 a 7,24 $\mathrm{cmol}_{\mathrm{c}} \mathrm{dm}^{-3}$ no solo TA, nas doses $0,0 \mathrm{t}$ $\mathrm{ha}^{-1}$ e $20,0 \mathrm{t} \mathrm{ha}^{-1}$, respectivamente. Os valores médios obtidos, portanto, foram de 3,68 $\mathrm{cmol}_{\mathrm{c}} \mathrm{dm}^{-3}$ para o solo TM e de 4,26 $\mathrm{cmol}_{\mathrm{c}} \mathrm{dm}^{-3}$ para o solo TA. 


\subsection{Capacidade de troca de cátions (CTC)}

A CTC (Figura 8) variou de 3,33 a 6,2 $\mathrm{cmol}_{\mathrm{c}} \mathrm{dm}^{-3}$ no solo TM (entre a dose 0,0 e $20 \mathrm{t} \mathrm{ha}^{-1}$ ). Para o solo TA, variou de 7,50 a $8,7 \mathrm{cmol}_{\mathrm{c}} \mathrm{dm}^{-3}$.

\subsection{Saturação por bases ( $\%$ \%)}

A V\% (Figura 9) variou de 8,5 a 98,2\% no solo TM e de 7,2 a $93,7 \%$ no solo TA, entre as doses 0,0 e 20,0 $\mathrm{t} \mathrm{ha}^{-1}$. Sendo que, as médias, para esse caso foram de $69,4 \%$ no solo TM e de $51,9 \%$ no solo TA.

\subsection{Saturação por alumínio}

A m\% (Figura 10) no solo TM variou de 1,68\% (na dose 20,0 $\mathrm{t} \mathrm{ha}^{-1}$ ) a $80,1 \%$ (na dose $0,0 \mathrm{t} \mathrm{ha}^{-1}$ ). Enquanto no solo TA, variou de $1,63 \%$ (na dose $0,0 \mathrm{t} \mathrm{ha}^{-1}$ ) a $69,2 \%$ (na dose $\left.20,0 \mathrm{t} \mathrm{ha}^{-1}\right)$. Na testemunha $\mathrm{m} \%$ foi de $79,7 \%$ para o solo TM e $68,0 \%$ para o solo TA.

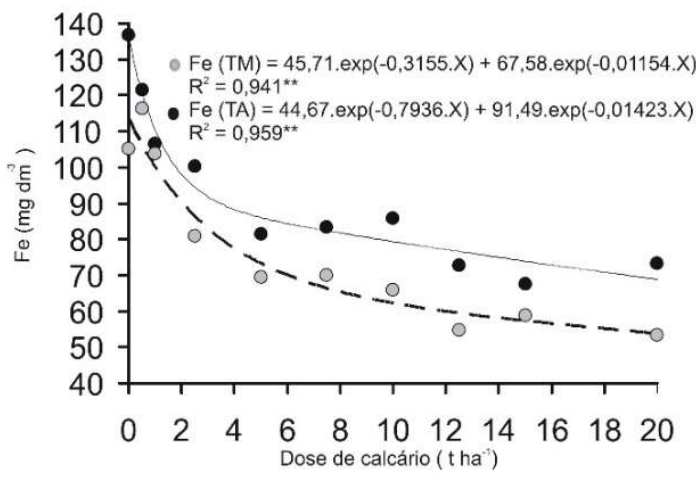

Figura 6. Teores de Fe nos solos com textura média (TM) e com textura argilosa (TA) em função das doses de calcário obtidas pelo método da incubação com $\mathrm{CaCO}_{3}$.

Figure 6. Fe content in soils with medium texture (TM) and clayey texture (TA) as a function of limestone rates obtained by the $\mathrm{CaCO}_{3}$ incubation method.

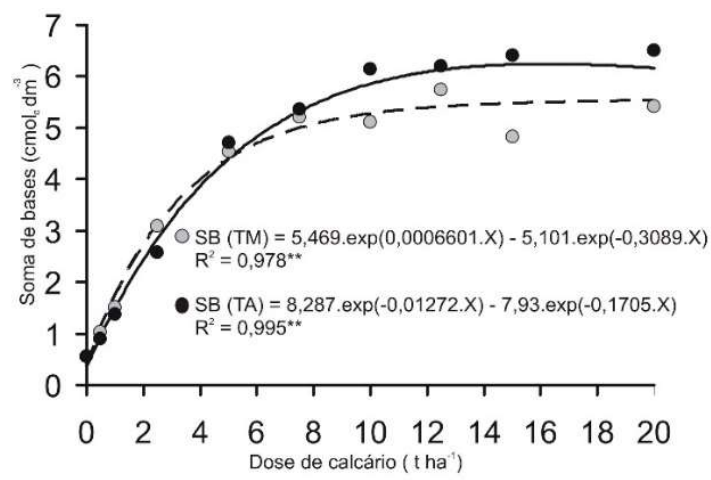

Figura 7. SB nos solos com textura média (TM) e com textura argilosa (TA) em função das doses de calcário obtidas pelo método da incubação com $\mathrm{CaCO}_{3}$.

Figure 7. SB in soils with medium texture (TM) and clayey texture (TA) as a function of the limestone doses obtained by the $\mathrm{CaCO}_{3}$ incubation method.

\section{DISCUSSÃO}

\subsection{Correlação entre as características químicas}

A função da correlação no presente trabalho foi esclarecer a similaridade de dispersão de cada atributo em relação às doses de calcário. Com base nesses dados, verificou-se que as variáveis em estudo se correlacionaram, tanto no solo argiloso (TA) quanto no solo com textura média (TM), como pode ser observado na Tabela 2.

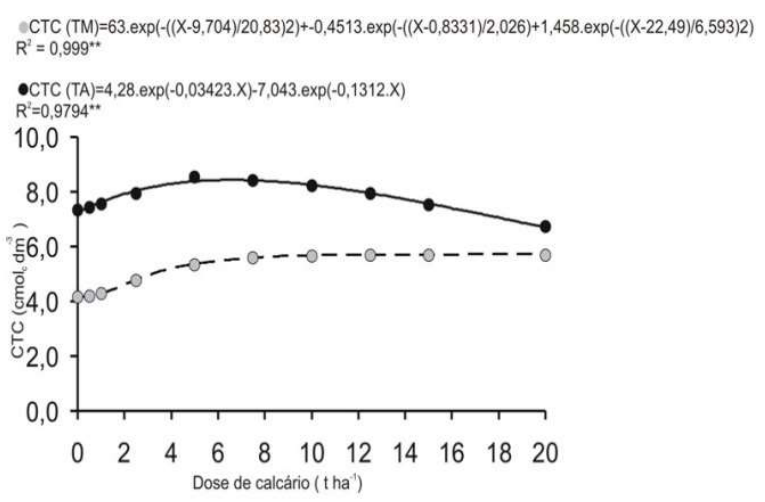

Figura 8. CTC nos solos com textura média (TM) e com textura argilosa (TA) em função das doses de calcário obtidas pelo método da incubação com $\mathrm{CaCO}_{3}$.

Figure 8. CTC in soils with medium texture (TM) and clayey texture (TA) as a function of limestone doses obtained by the $\mathrm{CaCO}_{3}$ incubation method.

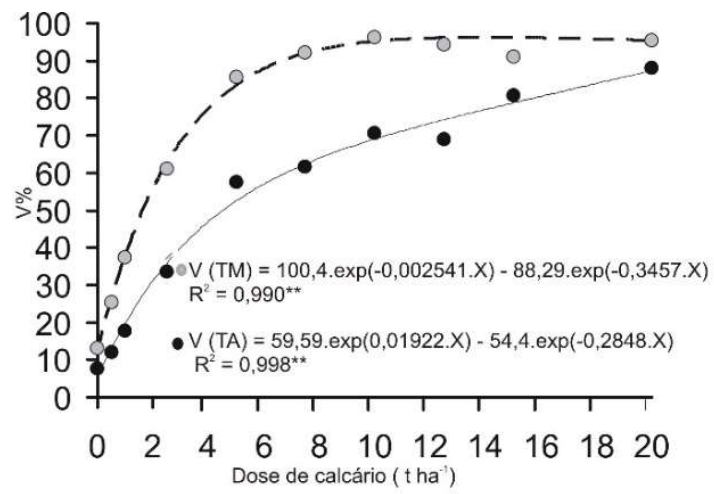

Figura 9. V\% nos solos com textura média (TM) e com textura argilosa (TA) em função das doses de calcário obtidas pelo método da incubação com $\mathrm{CaCO}_{3}$.

Figure 9. V\% in soils with medium texture (TM) and clayey texture (TA) as a function of limestone doses obtained by the $\mathrm{CaCO}_{3}$ incubation method.

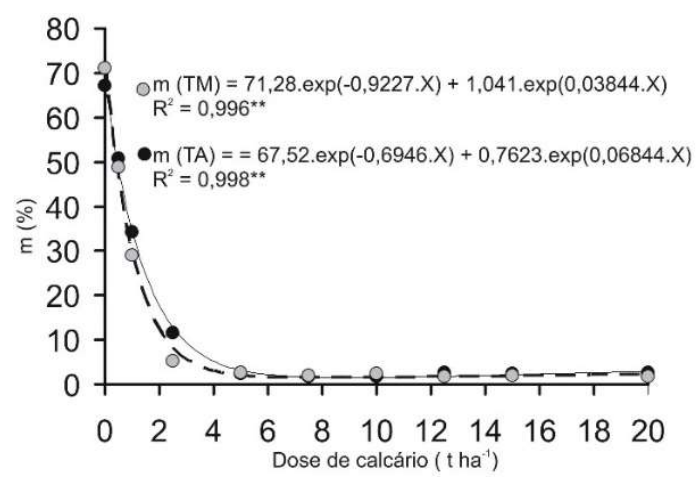

Figura 10. $\mathrm{m} \%$ nos solos com textura média (TM) e com textura argilosa (TA) em função das doses de calcário obtidas pelo método da incubação com $\mathrm{CaCO}_{3}$.

Figure $10 . \mathrm{m} \%$ in soils with medium texture (TM) and clayey texture (TA) as a function of limestone doses obtained by the $\mathrm{CaCO}_{3}$ incubation method.

Foram observadas correlações entre $\mathrm{pH}, \mathrm{Ca}, \mathrm{Mg}, \mathrm{SB}$, CTC e pH em $\mathrm{CaCl}_{2}$ e $\mathrm{V} \%$, nos dois tipos de solos. Isso ocorre porque a calagem eleva a $\mathrm{V} \%$, já que a rocha calcária possui $\mathrm{Ca}$ e $\mathrm{Mg}$ em sua composição, fazendo com que o calcário possua caráter alcalinizante. $\mathrm{Ca}$ e $\mathrm{Mg}$ são elementos que se comportam como bases no solo. Dessa forma, a 
elevação de seus teores tem como consequência, a elevação nos valores de SB, de CTC e da própria V\%.

Em contrapartida, a acidificação está relacionada com a liberação de $\mathrm{H}^{+}$na solução do solo, porque esse elemento é um agente de acidez (Da Ros et al., 2017) e, portanto, tem a capacidade de reduzir o $\mathrm{pH}$. A redução do $\mathrm{pH}$ contribui para o aumento no teor de $\mathrm{Al}^{3+}$ e, dessa forma, para o aumento de $\mathrm{m} \%$.

Em ambos os solos, as correlações entre os teores de Fe, $\mathrm{H}, \mathrm{Al}$, e de $\mathrm{m} \%$ foram negativas com as doses de calcário. $\mathrm{O}$ Fe é um micronutriente catiônico, que terá seu teor reduzido com o aumento da quantidade de calcário, como citado por Freitas et al. (2017) e Oliveira et al. (2015). Caso esta quantidade eleve o $\mathrm{pH}$ do solo para valores mais próximos do nível básico. O mesmo comportamento se observa para $\mathrm{H}$ e $\mathrm{Al}$, cujos teores serão reduzidos ao aumentar o $\mathrm{pH}$ do solo (SOUSA et al., 2014; MARTINS et al. 2015), podendo atingir, no caso do $\mathrm{Al}$, o valor de $0,0 \mathrm{cmol}_{\mathrm{c}} \mathrm{dm}^{-3}$ (MEERT et al., 2016; DA ROS et al., 2017). Consequentemente, esse resultado afetará o valor de $\mathrm{m} \%$, que nada mais é do que o percentual das cargas negativas dos coloides do solo, ocupadas por Al.

As doses de calcário tiveram influência positiva nos teores de $\mathrm{P}$ disponíveis, assim com observado por Da Ros et al. (2017), após aplicação de água residuária de suíno (ARS) que, no estudo citado, apresentou caráter alcalinizante. Sendo maior no solo com textura média. Como a calagem reduz o teor de $\mathrm{Al}$ disponível, contribui para a redução de um dos elementos que promove a precipitação do $\mathrm{P}$.

Para os micronutrientes ( $\mathrm{Zn}, \mathrm{Mn}$ e $\mathrm{Cu}$ ), a maior correlação com as doses de $\mathrm{CaCO}_{3}$ foi em solo TA. Provavelmente, devido à maior capacidade de retenção da argila, já que essa fração granulométrica do solo tem a função de reter nutrientes, sendo que, nas condições de solos de Cerrado, que são, geralmente, muito intemperizados, as argilas podem conter cargas negativas, favorecendo, dessa forma, a retenção dos micronutrientes catiônicos referidos. De acordo com Giácomo et al. (2015) isso pode se dar em função, também, dos maiores teores de matéria orgânica em solos mais argilosos. Sendo que, tanto argila quanto a matéria orgânica são capazes, ainda, de reter pelo processo de adsorção.

Segundo Weber et al. (2005), a fração argila dos solos das regiões de clima tropical, que são áreas em avançado grau de intemperização, apresentam minerais com carga elétrica variável, que podem modificar com a profundidade do solo. Essas características dependerão da mineralogia desse solo.

Para as características químicas nas quais se observou significância, efetuou-se o ajuste das equações de regressão (Tabela 3) e estas características serão discutidas a seguir.

\subsection{Acidez ativa ou $\mathrm{pH}$}

Após a incubação com calcário foi possível observar que os valores do $\mathrm{pH}$ em $\mathrm{CaCl}_{2}$ (Figura 1) foram classificados como baixo e muito alto, respectivamente, nas doses 0,0 e 20,0 t ha ${ }^{-1}$, segundo classificação realizada por Sousa; Lobato (2004), tanto em solos TM quanto TA.

No solo TM observou-se que os valores de $\mathrm{pH}$ em $\mathrm{CaCl}_{2}$ apresentaram-se com maior amplitude quando comparado ao solo TA. O que, provavelmente, esteja ligado às características do poder tampão de cada solo, que desfavorece a variação de $\mathrm{pH}$ do solo. Em pesquisa de Freitas et al. (2017) os maiores valores médios de $\mathrm{pH}$, verificados na área sob cultivo, foram em decorrência da calagem. Porém, esses valores médios de $\mathrm{pH}$ variaram de 3,75 a 6,2, que, de acordo com os autores sugere adequadas condições para a disponibilidade da maioria dos nutrientes, principalmente em solos com valores mais próximos ao 6,2.

No presente trabalho, o $\mathrm{pH}$ em $\mathrm{CaCl}_{2}$, nos dois solos, apresentaram ajuste exponencial com as doses de calcário, devido ao aumento do $\mathrm{pH}$ em função da dose de calcário aplicada. Apesar do aumento do $\mathrm{pH}$ ter maior destaque no solo TM, a tendência foi de estabilização do $\mathrm{pH}$ mais rapidamente nesse solo, o que ocorreu a partir da dose de 7,5 t ha ${ }^{-1}$.

Martins et al. (2015) também observaram o efeito da calagem no aumento do $\mathrm{pH}$ e dos teores de $\mathrm{Ca}$ e $\mathrm{Mg}$, bem como na redução dos teores de $\mathrm{Al}$ trocável e da acidez potencial nas áreas agrícolas, o que aumentou $\mathrm{V} \%$ nas áreas de cultivo agrícola.

Meert et al. (2016) estudando os efeitos da calagem sobre os atributos químicos do solo, verificaram que a calagem superficial em plantio direto aumentou o $\mathrm{pH}$ do solo e os teores de $\mathrm{Ca}^{2+}$. Além de ter diminuído os teores de $\mathrm{Al}^{3+}$ até $10 \mathrm{~cm}$ de profundidade, após um período de cinco meses.

Ao contrário do que se observou após a aplicação de calcário, o pH no solo testemunha variou entre 3,78 e 4,11. Valores que foram classificados como baixos. Essa foi a tendência tanto para solos TM quanto para solos TA. O que implica em mencionar que, nesses casos, os solos não estão favoráveis pra o crescimento da maioria das plantas mais cultivas atualmente, principalmente, em se tratando de espécies anuais. Comprovando a necessidade da calagem para essas condições de solo.

$\mathrm{O}$ aumento do $\mathrm{pH}$ em função da prática da calagem, além de diminuir os teores de $\mathrm{Al}$ tóxico promove o aumento da disponibilidade de alguns nutrientes. No entanto, a elevação do $\mathrm{pH}$ acima de 7 diminui a disponibilidade de outros nutrientes como: $\mathrm{P}, \mathrm{Zn}, \mathrm{Cu}, \mathrm{Mn}$ e Fe. Por isso, deve-se atentar para doses elevadas de calcário, que podem provocar a supercalagem.

\subsection{Acidez não trocável ou $\mathbf{H}^{+}$}

$\mathrm{O}$ teor de $\mathrm{H}^{+}$diminuiu com o aumento das doses de calcário (Figura 2), ou seja, observou-se uma relação inversa entre o teor de $\mathrm{H}^{+}$e a dose de calcário. Resultados esperados, já que a $\mathrm{OH}^{-}$liberada pelo calcário, após sua reação no solo, tem a capacidade de se ligar ao $\mathrm{H}^{+}$.

Em estudo, Caires (2010) atribuiu os menores valores de acidez potencial, observados no sistema de plantio convencional, devido ao fato da adição de calcário fornecer ânions $\mathrm{OH}^{-}$e $\mathrm{HCO}_{3}^{-}$que são receptores de $\mathrm{H}^{+}$, deixando, desta maneira, os coloides disponíveis para a ligação de $\mathrm{Ca}^{2+}$ e $\mathrm{Mg}^{2+}$, anteriormente ocupados por $\mathrm{H}^{+}$e $\mathrm{Al}^{+}$.

$\mathrm{Na}$ Figura 2, também foi possível observar que, inicialmente, os valores da acidez não trocável no solo TA, foram superiores aos do solo TM. Porém à medida que houve a aplicação de doses crescentes de calcário, ocorreu redução no teor de $\mathrm{H}^{+}$, até atingirem valores próximos à zero.

Em detrimento a isso, pode-se dizer que, os aumentos do $\mathrm{pH}$ são conhecidos e atribuídos à neutralização dos íons $\mathrm{H}^{+}$ pelos íons $\mathrm{OH}^{-}$, na fase sólida do solo, e à ocupação dos sítios de troca por $\mathrm{Ca}^{2+}$ e $\mathrm{Mg}^{2+}$, adicionados via $\mathrm{CaCO}_{3}$ e $\mathrm{MgCO}_{3}$. O que provoca acréscimos dos níveis de $\mathrm{V} \%$, com o uso de doses crescentes de carbonato (SOUSA et al., 2007). Bambolim et al. (2015) também observaram que a aplicação 
de calcário convencional foi eficaz na correção da acidez do solo, resultando no aumento do $\mathrm{pH}$ e, consequentemente, na redução da acidez potencial $(\mathrm{H}+\mathrm{Al})$.

Diante desses resultados, foi possível inferir que os valores de $\mathrm{H}^{+}$no solo TA foram mais altos porque esse solo tem maior teor de argila e de matéria orgânica, que têm maior capacidade de adsorver íons $\mathrm{H}^{+}$nos grupamentos carboxílicos e fenólicos, maior CTC e, consequentemente, maior poder tampão. Na prática, isso representa maior gasto de calcário para elevar o $\mathrm{pH}$ do solo.

\subsection{Acidez trocável ou $\mathrm{Al}$ trocável}

Os teores de Al (Figura 3) no solo TM e solo TA diminuíram com as doses de calcário. Esses resultados são semelhantes aos que foram observados para os teores de $\mathrm{H}^{+}$. $\mathrm{E}$, no caso do $\mathrm{Al}$, ocorre porque esse elemento também tem seu teor reduzido com a calagem já que, tanto $\mathrm{Al}$ quando $\mathrm{H}$ proporcionam caráter ácido ao solo.

Com o aumento das doses de calcário houve a redução no teor de Al trocável, que pode ser tóxico para as plantas, assim como ocorreu a elevação no $\mathrm{pH}$ do solo. Verificandose que, as doses acima de $5 \mathrm{t} \mathrm{ha}^{-1}$ foram mais eficientes para neutralizar a acidez trocável dos solos avaliados.

A calagem promove a precipitação do $\mathrm{Al}$ trocável do solo, sob a forma de hidróxido. Por isso, foi possível observar valores muito próximos a $0,0 \mathrm{cmol}_{\mathrm{c}} \mathrm{dm}^{-3}$. Esse teor de $\mathrm{Al}$ é importante dentro de uma área de cultivo, porque a presença do $\mathrm{Al}$ reduz o crescimento e o desenvolvimento das raízes e, consequentemente, a absorção de nutrientes, podendo prejudicar seu desenvolvimento (SIMON et al., 2016).

\subsection{Cálcio}

Os teores de Ca (Figura 4) aumentaram com as doses de calcário, variando de baixo a adequado, respectivamente, de acordo com classificação de Sousa; Lobato (2004), para os solos TM e TA, nas doses de 0,0 e de 20,0 $\mathrm{t} \mathrm{ha}^{-1}$, respectivamente.

Bambolim et al. (2015) verificaram que a aplicação de doses crescentes de calcário resultou em aumento linear no teor de Ca. No presente caso, o aumento foi exponencial, tendendo à estabilidade com a dose de calcário aplicada (a partir de $10 \mathrm{t} \mathrm{ha}^{-1}$ ).

As menores doses de calcário (até $4 \mathrm{t} \mathrm{ha}^{-1}$ ) não possibilitaram aumento dos teores de Ca a níveis que são adequados para as plantas, nos solos estudados. A partir da dose de $4 \mathrm{t} \mathrm{ha}^{-1}$, se observou aumento efetivo, nos teores de $\mathrm{Ca}$, principalmente em solos TA. Isso se deve à textura mais argilosa do mesmo que, por possuir maior superfície de reação que o solo TM, possibilitou maior dissolução do calcário aplicado ao solo. Melo et al. (2006) verificaram que em solos argilosos ocorreu maior retenção dos cátions $\mathrm{K}^{+}$, $\mathrm{Na}^{+}, \mathrm{Ca}^{2+} \mathrm{e} \mathrm{Mg}^{2+}$, o que é, portanto, influenciado pela textura do solo. Além disso, de acordo com Vitti et al. (2006) a baixa mobilidade do Ca no perfil do solo em razão da sua retenção nas cargas negativas das argilas e da matéria orgânica, podem favorecer os teores de Ca disponíveis após a aplicação de calcário.

Esse aumento nos teores de Ca também está relacionado com o próprio calcário, que possui $\mathrm{Ca}$ em sua constituição, na forma de $\mathrm{CaCO}_{3}$. Meert et al. (2016) observaram que o teor de $\mathrm{Ca}^{2+}$ apresentou comportamento semelhante ao do $\mathrm{pH}$, aumentando na camada de $0-10 \mathrm{~cm}$ do solo em função da calagem. E atribuíram esse aumento ao fato de o calcário ser fonte desse nutriente.
No entanto, é importante considerar que, conforme o valor do $\mathrm{pH}$ e os níveis de $\mathrm{Ca}$ adicionados ao solo, pode haver supercalagem, o que pode implicar em menor concentração de íons no solo, em razão da precipitação de fosfato com Ca, neutralização de $\mathrm{Al}^{3+}$ e do fluxo de íons da solução para a fase sólida, pela maior adsorção de metais aos coloides do solo (CARMO; SILVA, 2016).

\subsection{Magnésio}

Os teores de $\mathrm{Mg}$ foram classificados como baixo a alto, tanto em solo TM quanto em solo TA, considerando a classificação dada por Sousa; Lobato (2004), para as doses de 0,0 e de 20,0 t ha-1, respectivamente. Sendo que, nas testemunhas, os teores de $\mathrm{Mg}^{2+}$ não atingiram, ao menos, 0,4 $\mathrm{cmol}_{\mathrm{c}} \mathrm{dm}^{-3}$, independentemente do tipo de solo e, por isso, foram considerados baixos. Esses resultados são justificáveis, pois se trata da adição de calcário dolomítico no solo, este calcário possui um maior teor de $\mathrm{Mg}$ na forma de $\mathrm{MgCO}_{3} \mathrm{em}$ sua composição, em comparação com o calcário calcítico.

Nos dois solos estudados, os teores de $\mathrm{Mg}^{2+}$ se mantiveram próximos até a dose de $5 \mathrm{t} \mathrm{ha}^{-1}$ de calcário. Porém, em doses maiores de calcário, os teores de $\mathrm{Mg}^{2+}$ foram superiores no solo $\mathrm{TA}$.

\subsection{Ferro}

Os teores de Fe (Figura 6) diminuíram com o aumento das doses de $\mathrm{CaCO}_{3}$, independentemente da textura do solo. Esses resultados foram observados porque a calagem aumenta o pH do solo que, por consequência, tende a reduzir os teores de micronutrientes catiônicos como o Fe, devido à sua precipitação.

De acordo com Freitas et al. (2017), o pH afeta a distribuição dos micronutrientes que estão associados aos diferentes componentes do solo. Por isso, esses autores observaram teores de Fe significativamente maiores em solo que não recebeu calagem, em comparação com os solos já manejados com a prática da calagem.

Nas testemunhas os teores médios de Fe foram de 113,30 $\mathrm{mg} \mathrm{dm}{ }^{-3}$ para $\mathrm{TM}$, e de $136,16 \mathrm{mg} \mathrm{dm}^{-3}$ para TA. Isso porque os solos de Cerrado, principalmente, os Latossolos (mesma classe dos solos em estudo), são ricos em minerais que possuem o Fe em sua composição.

\subsection{Soma de bases (SB)}

A SB (Figura 7) apresentou resultados que estão coerentes com o que se observou quando os teores de Ca e de $\mathrm{Mg}$ foram analisados, ou seja, o aumento das médias para SB após a aplicação de calcário. Isso já poderia ser esperado porque $\mathrm{Ca}$ e $\mathrm{Mg}$ são bases no solo, o que favoreceu o aumento da SB, que, por sua vez, elevou a CTC (Figura 8) e a V\% (Figura 9) do solo. Esses resultados culminaram, como consequência, no aumento do $\mathrm{pH}$ do solo (Figura 1). No entanto, deve-se atentar para doses elevadas de calcário, que podem elevar essas características químicas a valores não desejáveis e prejudicar a dinâmica dos elementos no solo, principalmente dos micronutrientes catiônicos $(\mathrm{Fe}, \mathrm{Cu}, \mathrm{Mn}$, Zn e Ni), como mencionado.

Considerando as diferentes texturas, a SB apresentou tendência linear até $6 \mathrm{tha}^{-1}$ de $\mathrm{CaCO}_{3}$. Em doses superiores, o aumento na $\mathrm{SB}$ não foi proporcional à dose de calcário. Nas doses acima de $10 \mathrm{t} \mathrm{ha}^{-1}$ de $\mathrm{CaCO}_{3}$ observou-se tendência de estabilização da curva de SB, em solos TA. 


\subsection{Capacidade de troca de cátions (CTC)}

A CTC (Figura 8) foi classificada, entre as doses de 0,0 e de 20,0 t ha-1 , como baixa e adequada, respectivamente, segundo classificação de Sousa; Lobato (2004), ao estudar o solo TM. Para o solo TA, independentemente da dose, os valores foram classificados como médios. O que ocorreu por conta do caráter alcalinizante do calcário, corroborando a sua importância na melhoria da fertilidade do solo.

Sabe-se que a CTC do solo é importante para a fertilidade do mesmo, pois indica a capacidade deste em adsorver cátions trocáveis, que irão servir de nutrientes para as plantas (CARNEIRO et al., 2009). A CTC é responsável pela retenção de $\mathrm{K}, \mathrm{Ca}, \mathrm{Mg}$, além dos nutrientes que são cátions metálicos como $\mathrm{Cu}, \mathrm{Fe}, \mathrm{Mn}$ e Zn (FREITAS et al., 2017).

Segundo Ronquin (2010), se a CTC do solo está ocupada por cátions essenciais como $\mathrm{Ca}, \mathrm{Mg}$ e $\mathrm{K}$, pode-se considerar este, um solo adequado para a nutrição das plantas. Em compensação, se grande parte da CTC estiver ocupada por cátions potencialmente tóxicos como $\mathrm{H}^{+}$e $\mathrm{Al}$, este será um solo pobre.

Na presente pesquisa, a CTC apresentou aumento até a dose de $4 \mathrm{t} \mathrm{ha}^{-1}$, acima dessa dose, observou-se, para o solo $\mathrm{TM}$, tendência de equilíbrio em 5,50 $\mathrm{cmol}_{\mathrm{c}} \mathrm{dm}^{-3}$. Esse aumento é importante para a fertilidade do solo, pois proporciona aos coloides maior capacidade de reter cátions como o $\mathrm{Ca}^{2+}, \mathrm{Mg}^{2+}$ e $\mathrm{K}^{+}$, que são nutrientes para as plantas (ZANDONÁ et al., 2015). Bambolim et al. (2015) verificaram que a CTC apresentou aumento linear com a aplicação de calcário. Nesse caso, os valores aumentaram de 2,39 $\mathrm{cmol}_{\mathrm{c}} \mathrm{dm}^{-3}$ no tratamento controle, para 3,36 $\mathrm{cmol}_{\mathrm{c}} \mathrm{dm}^{-}$ 3 na maior dose aplicada $\left(2,5 \mathrm{Mg} \mathrm{ha}^{-1}\right)$.

\subsection{Saturação por bases (V\%)}

A V\% (Figura 9) variou entre baixa e muito alta, respectivamente, segundo classificação de Sousa; Lobato, para as doses de 0,0 e de 20,0 $\mathrm{t} \mathrm{ha}^{-1}$, dentre os solos analisados. Indicando que as maiores doses de calcário, aqui trabalhadas (a partir de 7,5 tha $\mathrm{ha}^{-1}$ para TM e entre 15 e $20 \mathrm{t}$ $\mathrm{ha}^{-1}$ para TA), podem não ser favoráveis, porque plantas que crescem em V\% muito alta podem apresentar deficiências, já que, nesse caso, alguns elementos podem se tornar insolúveis, principalmente, quando se tratam dos micronutrientes catiônicos.

Corroborando com a maior capacidade tampão do solo, devido ao teor de argila, que fez com que $\mathrm{V} \%$ fosse superior em TM. Vargas; Marques (2017) também observaram a importância da calagem no aumento de V\%. Esses autores verificaram que apenas nas menores doses, estudadas, de calcário $(\mathrm{V}=20$ e 30\%) não ocorreu neutralização total do $\mathrm{Al}$ e aumento do $\mathrm{pH}$.

Porém, verificou-se que, $\mathrm{V} \%$ teve a mesma tendência nos dois solos, em função do aumento nas doses de calcário. Essa tendência se deve à neutralização da acidez do solo, à neutralização do Al trocável e ainda, ao fornecimento de cátions básicos como Ca e $\mathrm{Mg}$ ao solo.

\subsection{Saturação por alumínio $(\mathrm{m} \%)$}

Nos dois solos estudados, $\mathrm{m} \%$ correlacionou-se negativamente com as doses de calcário (Figura 10) e consequentemente com os valores de $\mathrm{pH}$. Apresentando valores que foram classificados como baixo e muito alto para os dois tipos de solo, para as doses 0,0 e 20,0 $\mathrm{t} \mathrm{ha}{ }^{-1}$, respectivamente.
Podendo-se observar os altos teores de Al trocável em condições naturais de solo (testemunha), que devem ser reduzidos para que não afetem o crescimento radicular da espécie a ser manejada nessa área.

$\mathrm{Da}$ Ros et al. (2017) observaram que $\mathrm{m} \%$ nas duas primeiras camadas avaliadas foi menor que $0,5 \%$, pois normalmente, em solos com $\mathrm{pH}$ superior a 5,5, a presença de Al trocável no solo tende a zerar. Isso foi corroborado por Vargas; Marques (2017) que observaram redução expressiva de $\mathrm{m} \%$ em todos os tratamentos que utilizaram calcário, com destaque para $\mathrm{V}=60 \%$, no qual, após 30 dias, $\mathrm{m} \%$ já se encontrava nula.

Pode-se constatar também que, $\mathrm{m} \%$ foi superior no solo TA até a dose de $4 \mathrm{t} \mathrm{ha}^{-1}$, sendo que em doses mais elevadas, os valores foram semelhantes. Assim, para neutralizar o Al do solo TA seria necessário utilizar maior quantidade de calcário do que em TM, devido ao seu maior poder tampão.

\section{CONCLUSÕES}

A aplicação de calcário no Latossolo Vermelho distrófico, alterou os teores de $\mathrm{Ca}, \mathrm{Mg}, \mathrm{H}, \mathrm{Al}$ e Fe; bem como os valores de $\mathrm{pH}, \mathrm{CTC}, \mathrm{V} \%$ e $\mathrm{m} \%$, tanto quando este solo se apresenta com textura média, quanto com textura argilosa.

Em geral, as variáveis químicas no solo com textura média (TM), apresentaram médias com menores variações, em função das doses crescentes de calcário. Sendo que, a partir da dose de $5,5 \mathrm{t} \mathrm{ha}^{-1}$, os valores de $\mathrm{pH}$ foram superiores a 6,0 e os teores de $\mathrm{Al}$ foram de $0,0 \mathrm{cmol}_{\mathrm{c}} \mathrm{dm}^{-3}$. Em função do aumento nos teores de $\mathrm{Ca}$ e de $\mathrm{Mg}$.

Em contrapartida, no solo com textura argilosa (TA), a aplicação de calcário resultou em variáveis com valores que apresentaram maior variação entre as doses aplicadas, com tendência crescente para $\mathrm{pH}, \mathrm{Ca}, \mathrm{Mg}, \mathrm{SB}$ e $\mathrm{V} \%$. Nesse tipo de solo a estabilidade se deu em doses acima de 7,5 $\mathrm{t} \mathrm{ha}^{-1}$, quando o $\mathrm{pH}$ atingiu valores superiores a 5,5 e o teor de $\mathrm{Al}$ foi igual a $0,0 \mathrm{cmol}_{\mathrm{c}} \mathrm{dm}^{-3}$. Indicando que este tipo de solo necessita de doses mais elevadas de calcário para provocar o aumento do seu $\mathrm{pH}$.

\section{REFERÊNCIAS}

BAMBOLIM, A.; CAIONE, G.; SOUZA, N. F.; SEBENJUNIOR, G. F.; FERBONINK, G. F. Calcário líquido e calcário convencional na correção da acidez do solo. Revista de Agricultura Neotropical, Cassilândia, v. 2, n. 3, p. 34-38, 2015. DOI: https://dx.doi.org/10.32404/rean.v2i3.277

BLUM, S. C.; CAIRES, E. F.; ALLEONI, L. R. F. Lime and phosphogypsum application and sulfate retention in subtropical soils under no-till system. Journal of Soil Science and Plant Nutrition, Temuco, v. 13, n. 2, p. 279-300, 2013. DOI: http://dx.doi.org/10.4067/S071895162013005000024

CAIRES, E. F. Manejo da acidez do solo. In: PROCHNOW, L. I.; CASARIN, V.; STIPP, S. R. Boas práticas para uso eficiente de fertilizantes. Piracicaba: IPNI, 2010. p. 276-347.

CARDOSO, A. A. S.; SANTOS, J. Z. L.; TUCCI, C. A. F.; FARIAS, E. P.; MOURA, R. P. M. Influência da acidez e do teor de fósforo do solo no crescimento inicial do mogno. Pesquisa Florestal Brasileira, Colombo, v. 35, $\begin{array}{lllll}\text { n. } 1, & \text { p. } 1-10, & 2015 . & \text { DOI: }\end{array}$ https://dx.doi.org/10.4336/2015.pfb.35.81.667 
CARMO, D. L.; SILVA, C. A. Condutividade elétrica e crescimento do milho em solos contrastantes sob aplicação de diversos níveis de calagem. Pesquisa Agropecuária Brasileira, Brasília, v. 51, n. 10, p. 1762 1772, 2016. DOI: http://dx.doi.org/10.1590/s0100204x2016001000008

CARNEIRO, M. A. C. Atributos físicos, químicos e biológicos de solo de cerrado sob diferentes sistemas de uso e manejo. Revista Brasileira de Ciência do Solo, Viçosa, v. 33, n. 1, p. 147-157, 2009. DOI: http://dx.doi.org/10.1590/S0100-06832009000100016

DA ROS, C. O.; SILVA, V. R.; SILVESTRIN, T. B.; SILVA, R. F.; PESSOTTO, P. P. Disponibilidade de nutrientes e acidez do solo após aplicações sucessivas de água residuária de suinocultura. Revista Brasileira de Tecnologia Agropecuária, Frederico Westphalen, v. 1, n. 1, p. 35-44, 2017.

EMBRAPA_EMPRESA BRASILEIRA DE PESQUISA AGROPECUÁRIA. Centro Nacional de Pesquisa do Solo. Manual de métodos de análise do solo. 2. ed. Brasília: EMBRAPA, 1997. 212 p.

FREITAS, L.; OLIVEIRA, I. A.; SILVA, L. S.; FRARE, J. C. V.; FILLA, V. A.; GOMES, R. P. Indicadores da qualidade química e física do solo sob diferentes sistemas de manejo. Unimar, Marília, v. 26, n. 2, p. 8-25, 2017.

GIÁCOMO, R. G.; PEREIRA, M. G.; GUARESCHI, R. F.; MACHADO, D. L. Atributos químicos e físicos do solo, estoques de carbono e nitrogênio e frações húmicas em diferentes formações vegetais. Ciência Florestal, Santa Maria, v. 25, n. 3, p. 617-631, 2015. DOI: http://dx.doi.org/10.5902/1980509819613

MARTINS, E. C. A.; PELUZIO, J. M.; OLIVEIRA JUNIOR, W. P.; TSAI, S. M.; NAVARRETE, A. A.; MORAIS, P. B. Alterações dos atributos físico-químicos da camada superficial do solo em resposta à agricultura com soja na várzea do Tocantins. Biota Amazônica, Macapá, v. 5, n. 4, p. 56-62, 2015. DOI: http:/ /dx.doi.org/10.18561/21795746/biotaamazonia.v5n4p56-62

MEERT, L.; MÜLLER, M. M. L.; ZANÃO JUNIOR, L. A.; MICHALOVICZ, L.; NASCIMENTO, R. Atributos químicos do solo e resposta do trigo à calagem superficial em sistema plantio direto. Brazilian Journal of Applied Technology for Agricultural Science, Guarapuava, v.9, n.3, p.45-51, 2016.

MELO, R. F.; FERREIRA, P. A.; MATOS, A. T.; RUIZ, H. A.; OLIVEIRA, L. B. Deslocamento miscível de cátions básicos provenientes da água residuária de mandioca em colunas de solo. Revista Brasileira de Engenharia Agrícola e Ambiental, Campina Grande, v. 10, n. 2, p. 456-465, 2006. DOI: http://dx.doi.org/10.1590/S141543662006000200029

OLIVEIRA, C. M. R.; PASSOS, R. R.; ANDRADE, F. V.; REIS, E. F.; STURM, G. M.; SOUZA, R. B. Corretivo da acidez do solo e níveis de umidade no desenvolvimento da cana-de-açúcar. Revista Brasileira de Ciências Agrárias, Recife, v. 5, n. 1, p. 25-31, 2010. DOI: http://dx.doi.org/10.5039/agraria.v5i1a541

OLIVEIRA, J. R.; SOUZA, F. V. P.; SILVA, U. T. G.; DUARTE, N. F.; PINTO, S. I. C. Saturação por bases para o cultivo do cedro australiano. Global Science and Technology, Rio Verde, v. 8, n. 2, p. 96-102, 2015. DOI: http:/ /dx.doi.org/10.14688/1984-3801/gst.v8n2p96102

RONQUIN, C. C. Conceitos de fertilidade do solo e manejo adequado para as regiões tropicais. Campinas: EMBRAPA Monitoramento por Satélite, 2010. (Boletim de Pesquisa e Desenvolvimento, n.8).

SIMON, C. A.; RONQUI, M. B.; ROQUE, C. G.; DESENSO, P. A. Z.; SOUZA, M. A. V. KÜHN, I. E.; CAMOLESE, H. S.; SIMON, C. P. Efeitos da queima de resíduos do solo sob atributos químicos de um latossolo vermelho distrófico do cerrado. Nativa, Sinop, v. 4, n. 4, p. 217-221, 2016. DOI: http://dx.doi.org/10.14583/2318-7670.v04n04a06

SOUSA, D. M. G.; LOBATO; E. Cerrado: Correção do solo e adubação. 2 ed. Brasília: EMBRAPA Informação Tecnológica, 2004. 416 p.

SOUSA, D. M. G.; MIRANDA, L. N.; OLIVEIRA, S. A. Acidez do solo e sua correção. In: NOVAIS, R. F.; ALVAREZ V., V. H.; BARROS, N. F.; FONTES, R. L. F.; CANTARUTTI, R. B.; NEVES, J. C. L. (Ed.). Fertilidade do solo. Viçosa: SBCS, 2007. p. 206-266.

SOUZA, L. F. R. A.; MARINHO, R. W. D.; NUNES, F. M.; COSTA, N. B.; NASCIMENTO, I. O.; SILVA, W. A. Incubação de Argissolo Vermelho Amarelo distrófico com aplicação de doses crescentes de $\mathrm{CaCO}_{3}$ para neutralização da acidez trocável. Agroecossistemas, Belém, v. 6, n. 1, p. 66-73, 2014. DOI: http://dx.doi.org/10.18542/ragros.v6i1.1847

VARGAS, G.; MARQUES, R. Crescimento e nutrição de angico e canafístula sob calagem e gessagem. Floresta e Ambiente, Seropédica, v. 24, p. 1-10, 2017. DOI: http://dx.doi.org/10.1590/2179-8087.010216

VITTI, G. C.; LIMA, E.; CICARONE, F. Cálcio, magnésio e enxofre. In: FERNANDES, M. S. (Ed.). Nutrição mineral de plantas. Viçosa: SBCS, 2006. p. 299-326.

WEBER, O. L. S.; CHITOLINA, J. C.; CAMARGO, O. A.; ALLEONI, L. R. F. Cargas elétricas estruturais e variáveis de solos tropicais altamente intemperizados. Revista Brasileira de Ciência do Solo, Viçosa, v. 29, n. 6, p. 867-873, 2005. DOI: http://dx.doi.org/10.1590/S0100-06832005000600004

ZANDONÁ, R. R.; BEUTLER, A. N.; BURG, G. M.; BARRETO, C. F.; SCHMIDT, M. R. Gesso e calcário aumentam a produtividade e amenizam o efeito do déficit hídrico em milho e soja. Pesquisa Agropecuária Tropical, Goiânia, v. 45, n. 2, p. 128-137, 2015. 